\title{
The growth and saponin production of Platycodon grandiflorum (Jacq.) A. DC. (Chinese bellflower) hairy roots cultures maintained in shake flasks and mist bioreactor
}

\author{
Natalia Urbańska', Joanna Giebułtowicz², Olga Olszowska', Wojciech J. Szypuła1* \\ 1 Department of Pharmaceutical Biology and Medicinal Plants Biotechnology, Medical University of Warsaw, Banacha 1, 02-097 Warsaw, Poland \\ 2 Department of Bioanalysis and Drug Analysis, Medical University of Warsaw, Banacha 1, 02-097 Warsaw, Poland
}

\section{Abstract}

The growth and saponin accumulation were measured in two lines of transgenic hairy roots of Platycodon grandiflorum, Pl 6 and Pl 17, cultured for 8 weeks in 250-ml shake flasks containing $50 \mathrm{ml}$ of hormone-free woody plant medium supplemented with $40 \mathrm{~g} / \mathrm{l}$ sucrose and in the Pl 17 line cultured for 12 weeks in a 5-1 mist bioreactor containing 1.51 of the same medium. With both methods, the growth of transgenic hairy roots was assessed as both fresh and dry weight and the biomass growth was correlated with the conductivity and sucrose uptake. The accumulation of saponins was measured and compared with that in roots derived from the field cultivation. The saponin concentrations were significantly higher in the two hairy root lines cultured in shake flasks [ $6.92 \mathrm{~g} / 100 \mathrm{~g}$ d.w. (g\%) and $5.82 \mathrm{~g} \%$ in Pl 6 and Pl 17, respectively] and the line cultured in the bioreactor $(5.93 \mathrm{~g} \%$ ) than in the roots derived from the field cultivation $(4.02 \mathrm{~g} \%)$. The results suggest that cultures of $P$. grandiflorum hairy roots may be a valuable source for obtaining saponins.

Keywords: Platycodon grandiflorum; Chinese bellflower; hairy roots; saponins; mist bioreactor

\section{Introduction}

Hairy, or transgenic roots are characterized by a rapid and stable growth, which importantly can be initiated and maintained in a hormone-free medium. They often synthetize approximately the same and in some cases even greater amounts of secondary metabolites compared to their mother plants $[1,2]$ and the rate of production remains stable. This makes hairy roots of medicinal plants a good source of valuable compounds and obviously their large-scale culture in bioreactors holds immense potential for the pharmaceutical industry [3].

Platycodon grandiflorum (Jacq.) A. DC. (Campanulaceae) is an ornamental plant growing wild in northern Asia, in China, Korea, Japan and east Siberia. For culture it needs light, medium moisture, organically rich, well-drained loams and full sun to part shade.

Platycodi radix, the root of $P$. grandiflorum, has been used as food and in traditional oriental medicine to treat bronchitis, asthma and other pulmonary diseases. Triterpene saponins, called platycosides, are responsible for the medicinal value of this plant material. They have demonstrated a broad spectrum of therapeutic effects, such as antitumor

\footnotetext{
* Corresponding author. Email: wszypula@wum.edu.pl
}

Handling Editor: Jan Rybczyński
[4-7], anti-inflammatory [8,9], hepatoprotective [10], antiatherosclerotic [11] and antinociceptive [12]. Additionally, these compounds were found to be a potent adjuvant of specific cellular and humoral immune responses, with the potential use in vaccine production [13-15]. Finally, saponins from Platycodi radix stimulated osteoblast differentiation via $R U N X 2$, a principal osteogenic master gene for bone formation [16].

Although the extensive pharmacological studies of these valuable compounds were undertaken, to date the sum of saponins, not the chosen, in hairy root cultures of P. grandiflorum was determined only by our research team [17]. Besides, this is the first report of the growth of $P$. grandiflorum transgenic roots cultured in a mist bioreactor and their yield of saponins. The method of Platycodi radix saponins determination published in "Chinese pharmacopeia" [18] exhibited as no suitable for quantitative analysis of saponins from P. grandiflorum transgenic roots. Therefore, the authors elaborated their own method [17].

The compounds mentioned above are the main chemicals found in Platycodi radix. They are typical composed of oleaene backbones with two side chains: one is a 3-O-glucose linked by glycosidic bond, and the other is a 28 -O-arabinoserhamnose-xylose-apiose linked by an ester bond [19]. To date, more than 55 triterpenoid saponins have been isolated from Platycodi radix [20]. Examples are platycodins A-I and polygalacins D and D2. According to WHO monographs 
standards [21] the content of saponins should exceed $2 \%$. An effective HPLC method to analyze 18 platycosides from three-year-old Chinese bellflower roots was developed. Amongst them platycoside E showed the highest content $(2.00 \mathrm{mg} / \mathrm{g})$, followed by polygalacin D2 (1.77 mg/g) and 3"-O-acetylplatyconic acid A (1.35 mg/g) [22]. Considerably smaller amounts of 7 platycosides in the wild and hairy roots of $P$. grandiflorum received Kim et al. [23]. It could be due to the other origin or age of the plants. No information is given about that in the article. Authors developed hairy roots of $P$. grandiflorum with inserted gene of 3-hydroxy3-methylglutaryl-coenzyme A reductase. This enzyme catalyzes the synthesis of triterpenoids. The highest level of total platycosides $(1.60 \pm 0.2 \mathrm{mg} / \mathrm{g})$ was detected in the T7 line, what was 2.5-fold higher than that of the controls.

Chemical investigation on Platycodi radix revealed that, apart from saponins, in this plant material phytosterols B-amyrin and $\alpha$-spinasterol [23], polycaetylene lobetyolin $(0.019 \%)$ [24], phenylpropanoid esters [25], a mixed compound of n-tetracosanoic acid (lignoceric acid), nhexacosanoic acid (cerotic acid), n-octacosanoic acid and a-monopalmitin [26], polysaccharides named PGPN, PGPA1, PGPA2 and PGPA3 [27], arabinogalactan PGAW1 [28], homogalacturonan PGA4-3b [linear poly-( $1 \rightarrow 4)-\alpha-D-$ galactopyranosyluronic acid] [29] and polyunsaturated fatty acids: linoleic acid (20\%), palmitic acid (7\%), stearic acid $(<1 \%)$ and oleic acid $(<1 \%)[30]$ are present.

Aerial parts of $P$. grandiflorum contain no saponins but phenolics, particularly luteolin-7-O-glucoside and apigenin-7-O-glucoside [31]. From seeds flavoplatycoside, grandoside and four flavonoids: (2R,3R)-taxifolin, quercetin 7-O-glucoside, luteolin-7-O-glucoside and quercetin 7-O-rutinoside were isolated [32]. Flowers of $P$. grandiflorum comprise the following constituents: apigenin, apigenin-7-O-B-D-glucopyranoside, apigenin7-O-(6"-O-acetyl)-B-D-glucopyranoside, luteolin, luteolin-7-O-B-D-glucopyranoside, luteolin-7-O-(6"-Oacetyl)-B-D-glucopyranoside, isorhamnetin-3-O-neohesperoside, 4-O-caffeoylquinic acid, chlorogenic acid methyl ester, 4-O-B-D-glucopyranosylcaffeic acid, lobetyolin, cordifolioidyne $\mathrm{C}$, isomultiflorenyl acetate, B-sitosterol glucoside and $\alpha$-spinosterol [33].

In vitro $P$. grandiflorum plants regeneration was elaborated by some scientists, including Urbańska et al. [34]. The aim was achieved by two ways: by somatic embryogenesis [35] or by two-step action: repeated shoot-section and following rooting of the developed new shoots $[34,36,37]$. In both methods developed plantlets, which grew to maturity in the soil.

Somatic embryogenesis was conducted as follows: mature zygotic embryos formed embryogenic calluses on Murashige and Skoog (MS) medium [38] supplemented with 2,4-dichlorophenoxyacetic acid $(2,4-\mathrm{D} ; 4.52 \mu \mathrm{M})$. From calli cell suspension culture was established using the same, but liquid, medium and the same phytohormone at the same dose. Following transfer to solid MS basal medium, cells gave rise to somatic embryos.

The MS medium was chosen as well for proliferation of shoots. For good proliferation rate medium should be supplemented with benzyladenine (BA; $4.4 \mu \mathrm{M})$ [36], with 2-isopenthenyladenine $(2 \mathrm{iP} ; 4.92 \mu \mathrm{M})$ and indole-3-acetic acid (IAA; $2.85 \mu \mathrm{M}$ ) [37], or with kinetine (KIN; $0.01 \mathrm{mg} / \mathrm{l}$ ) and $\alpha$-naphtaleneacetic acid (NAA; $0.01 \mathrm{mg} / \mathrm{l}$ ) [34]. The highest rate of rooting of obtained shoots was induced on MS medium containing $4.90 \mu \mathrm{M}$ or $9.80 \mu \mathrm{M}$ indole-3-butyric acid (IBA) [37], $0.49 \mu \mathrm{M}$ IBA [36] or on half-strength MS medium with IBA $(0.05 \mathrm{mg} / \mathrm{l})$ and saccharose ( $40 \mathrm{~g} / \mathrm{l})$ [34]. The medium enrichment on saccharose at a dose $40 \mathrm{~g} / \mathrm{l}$ profitably influenced on the plantlets development, both shoots and roots [34]. The root, shoot and leaf thickness was found to be increased, while the length of shoots was decreased.

Urbańska elaborated the best conditions for maintenance the culture of non-transformed roots of $P$. grandiflorum (data not published). As the explants the plantlets growing by three passages on half-strength MS (MS/2) medium with IBA $(1 \mathrm{mg} / \mathrm{l})$ and saccharose $(40 \mathrm{~g} / \mathrm{l})$ were used. The roots were cut from the shoots and their growth was tested on the following liquid media: MS/2, Gamborg medium (B5) [39] and woody plant medium (WPM) [40] full or half-strength media all with NAA $(1 \mathrm{mg} / \mathrm{l})$ and saccharose $(40 \mathrm{~g} / \mathrm{l})$, the last mentioned also with IBA $(1 \mathrm{mg} / \mathrm{l})$ instead of NAA. The best for growing proved to be WPM medium with IBA $(1 \mathrm{mg} / \mathrm{l})$ and saccharose $(40 \mathrm{~g} / \mathrm{l})$.

Besides $P$. grandiflorum, the other plants, which accumulate triterpene saponins in their roots, occur in the nature. They belong to genus Panax and Glycyrrhiza. For both genuses in vitro culture of different cells and tissues have been established successfully.

For many years the ability to increase secondary metabolites production by colchicine is used in the practice. For this purpose, the seeds of Glycyrrhiza glabra var. glandulifera were treated with colchicine. The amount of glycyrrhizic acid, the main biologically active saponin among that produced by licorice (Glycyrrhiza), in callus formed from the plantlets grown from seeds treated with colchicines increased [41]. The other way to enhance the amount of glycyrrhize acid is the employment of elicitors. Methyl jasmonate was most efficient in increment glycyrrhize acid production in G. inflata hairy roots. What is more, sucrose (6\%) was optimal for growth and glycyrrhizic acid accumulation [42]. The ammonia/nitrate ratio and phosphate concentration influence glycyrrhizic acid accumulation as well. The content of glycyrrhize acid in adventitious roots of G. uralensis reached the optimum $(0.47 \mathrm{mg} / \mathrm{g})$ at an ammonia/nitrate ratio of $15: 15$ and when $0.625 \mu \mathrm{M}$ phosphate was applicated [43]. The method of elicitation to improve glycyrrhizic acid productiveness was applied in the roots of 65-day old plants of G. glabra. Treatment of plantlets with $0.1-2 \mathrm{mM}$ of methyl jasmonate or with 0.1 and $1 \mathrm{mM}$ salicylic acid enhanced the production of glycyrrhizic acid, as compared to the controls [44]. There are the other ways for increasing the amount of glycyrrhizic acid. In the hairy roots of $G$. uralensis with inserted gene of squalene syntase, the enzyme, which plays a regulatory role in the biosynthesis of triterpene saponins, the highest glycyrrhizic acid content was obtained [45]. Finally, it worth to add that the scaleup of the suspension culture of G. inflata was established successfully in a bioreactor with a low-shear impeller [46]. The balloon-type bubble bioreactor can be utilized as well to provide a suspension culture [47]. 
Elicitation as the method for increase Panax ginseng saponins, known as ginsenosides, was used in hairy root culture of this species [48]. Jasmonic acid in the range 4.8-23.8 $\mu \mathrm{M}$ strongly improved total ginsenosides production. The same elicitor at $2.0 \mathrm{mg} / \mathrm{l}$ increased significantly ginsenoside yield in adventitious root culture of $P$. ginseng in flasks and balloon type airlift bioreactor [49]. The other elicitor, vanadate at a dose $50 \mu \mathrm{M}$, was used successfully to improve ginsenoside production in suspenson cultures of $P$. ginseng [50].

Initial sucrose concentration and inoculum size influence ginseng saponin production by suspension culture of $P$. ginseng. The maximum saponin production of $275 \mathrm{mg} / \mathrm{l}$ was achieved at $6 \mathrm{~g} / \mathrm{l}$ of inoculum size and $60 \mathrm{~g} / \mathrm{l}$ initial medium sucrose [51]. Temperature and light quality influence ginsenoside production by hairy root culture of $P$. ginseng in the bubble bioreactor. Ginsenoside production was optimal under $20^{\circ} \mathrm{C} / 13^{\circ} \mathrm{C}$ day $(12 \mathrm{~h}) /$ night $(8 \mathrm{~h})$ cycle. Ginsenoside accumulation was optimum in the cultures grown under fluorescent light [52]. Comprehensive review of influence of various factors on ginsenoside production published $\mathrm{Wu}$ and Zhong [53].

\section{Material and methods}

\section{Hairy root culture induction}

Hairy roots of Platycodon grandiflorum were established using Agrobacterium rhizogenes ATCC 15834 [17]. The bacteria were grown on yeast mannitol broth (YMB) solid medium [54] for $120 \mathrm{~h}$ at $25^{\circ} \mathrm{C}$, in the dark. Next, single colonies were inoculated into yeast extract broth (YEB) liquid medium [55] with acetosyringone $(0.2 \mathrm{mg} / \mathrm{l}) 72 \mathrm{~h}$ at $25^{\circ} \mathrm{C}$, in the dark, with continuous shaking. The bacterial cultures were diluted (1:4) with YEB liquid medium before transformation. The leaves and stems of 50 micropropagated plants developed from the seeds and next growing for three passages on the MS/2 medium with IBA $(1 \mathrm{mg} / \mathrm{l})$ and saccharose $(40 \mathrm{~g} / \mathrm{l})$ were directly wounded with a sterile needle containing bacterial suspension. The explants were cultured on phytohormone-free MS solid medium with sucrose $(40 \mathrm{~g} / \mathrm{l})$, for $96 \mathrm{~h}$ at $25^{\circ} \mathrm{C}$, in the dark, and then transferred to the same medium with the addition of Claforan ${ }^{\circledR}(500$ $\mathrm{mg} / \mathrm{l})$. The roots emerged at the wounding site after 15 days of incubation under $40 \mu \mathrm{mol} \mathrm{m}{ }^{-2} \mathrm{~s}^{-1}$ fluorescent lights for $18 \mathrm{~h}$ per day (Fig. 1 ).

To prove the transformed nature of hairy roots PCR analysis was done. Total genomic DNA was extracted from hairy roots using DNeasy Plant Mini Kit (Qiagen, USA). Primers for detecting rolA gene (5'-CGT TGT CGG AAT GGC CCA GAC C-3' and 5'-CGT AGG TCT GAA TAT TCC GGT CC-3'), rolB gene (5'-CGT TGT CGG AAT GGC CCA GAC C-3' and 5'-CGT AGG TCT GAA TAT TCC GGT CC$3^{\prime}$ ) and rolC gene (5'-TGT GAC AAG CAG CGA TGA GC-3' and 5'-GAT TGC AAA CTT GCA CTC GC-3') were used in amplification process. Primers amplified a 248-bp fragment of rolA coding region, 652-bp fragment of $\mathrm{rolB}$ coding region and a 490-bp fragment of rolC coding region respectively. Primers for detecting the $\operatorname{virC}$ gene (5'-ATCATTTGTAGC GACT-3' and 5'-AGCTCAAACCTGCTTC-3') outside the T-DNA of Ri plasmid were also used to eliminate the possibility of $A$. rhizogenes contamination of the hairy roots lines. The negative controls were DNA from non-transformed roots, clone number 26 and positive control was A. rhizogenes, strain ATCC 15834 respectively. The amplification conditions for rolA and rolC were as follow: 2 min melting at $94^{\circ} \mathrm{C}$ followed by 35 cycles of a 1 min melting at $94^{\circ} \mathrm{C}$, a 1 minute annealing at $55^{\circ} \mathrm{C}$ and $1 \mathrm{~min}$ elongation at $72^{\circ} \mathrm{C}$ and final elongation for $5 \mathrm{~min}$ at $72^{\circ} \mathrm{C}$. The amplification conditions for rolC were as follow: 3 min melting at $94^{\circ} \mathrm{C}$ followed by 30 cycles of a $1 \mathrm{~min}$ melting at $94^{\circ} \mathrm{C}$, a 1 minute annealing at $55^{\circ} \mathrm{C}$ and $1 \mathrm{~min}$ elongation at $72^{\circ} \mathrm{C}$ and final elongation for $5 \mathrm{~min}$ at $72^{\circ} \mathrm{C}$. PCR products were visualized by electrophoretic separation on $1 \%(\mathrm{w} / \mathrm{v})$ agarose gels in $1 \times$ TBE buffer and staining with ethidium bromide.

\section{Hairy root culture in shake flasks}

Two hairy root lines (Pl 6, Pl 17) showing rapid growth were maintained in 250-ml Erlenmyer flasks with $50 \mathrm{ml}$ of hormone-free WPM liquid medium with sucrose (40 g/l), which proved to be the best for optimal growth. The $\mathrm{pH}$ value was adjusted to 5.7 before autoclaving. The culture was incubated in the dark at $25^{\circ} \mathrm{C}$ on a rotary shaker (100 rpm) and subcultured every six weeks. The average inoculum size was $0.4 \pm 0.1 \mathrm{~g}$ fresh weight, which corresponded to $0.04 \mathrm{~g}$

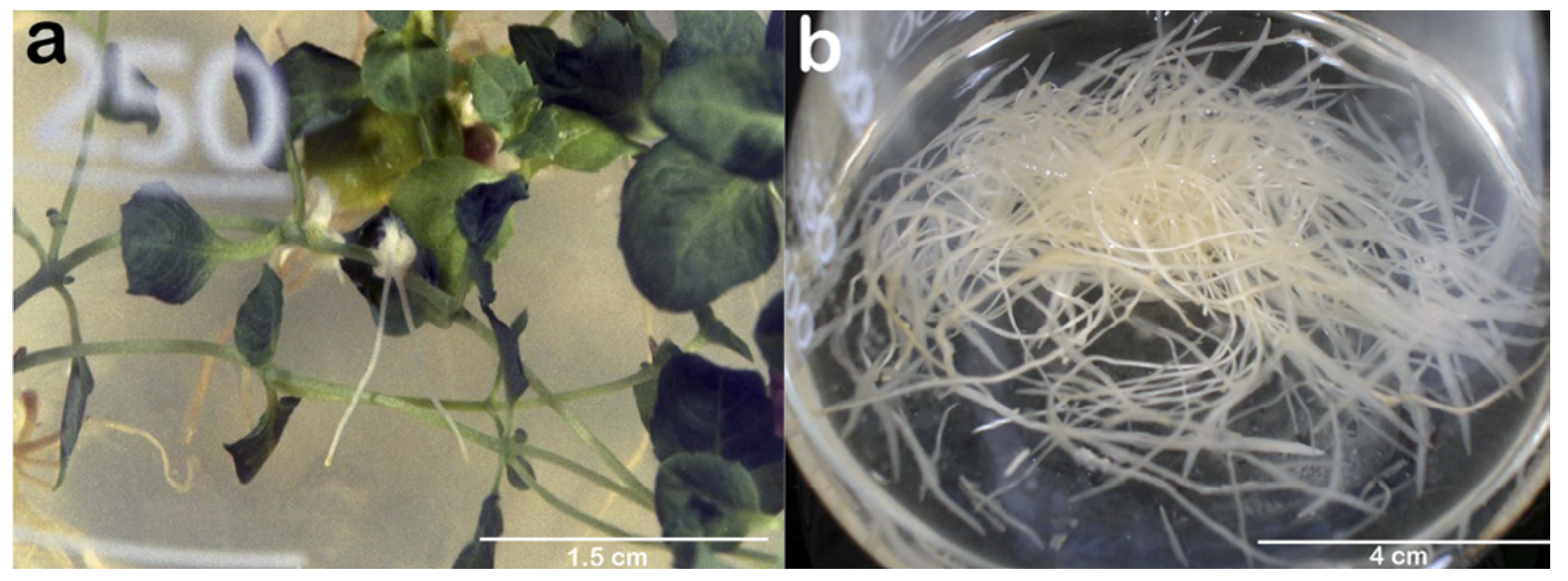

Fig. 1 a Platycodon grandiflorum hairy roots growing from inoculated site of plantlet, week 2 after inoculation. b Hairy roots on hormone-free WPM medium with sucrose (40 g/l). Culture week 2. 
of dry biomass. After 14 passages, the transgenic line $\mathrm{Pl} \mathrm{17,}$ whose growth was superior to that the Pl 6 line, was used for studies in a bioreactor.

\section{Hairy root culture in a bioreactor}

The mist bioreactor used in this study measured 400 $\mathrm{mm}$ in height and $200 \mathrm{~mm}$ in diameter. It consisted of one 5l-glass vessel fitted with a stainless steel mesh placed at the level of $150 \mathrm{~mm}$ from the bottom. The air inlet and the air outlet with filters were situated on the top of the column. The initial volume of the medium was 1.51 . A peristaltic pump (MasterFlex ${ }^{\circledast}$ L/S, Cole Pomer, USA) maintained recirculation and dosing of the hormone-free WPM medium supplemented with $40 \mathrm{~g} / \mathrm{l}$ sucrose through a polypropylene dispersal nozzle situated at the level of $70 \mathrm{~mm}$ from the bottom of the vessel. The operating time of the pump was $60 \mathrm{~s}$ with the medium supplied at $10 \mathrm{~s}$ intervals. The air flow rate was $0.4 \mathrm{l} / \mathrm{min}$. The bioreactor was inoculated with four fragments of hairy roots. The inoculum size was $18 \mathrm{~g}$ fresh weight, which was proportional to the inoculum size $0.4 \mathrm{~g}$ in $50 \mathrm{ml}$ of medium in the shake flasks. The roots grew at $23^{\circ} \mathrm{C}$, in the dark, for 12 weeks. After 8 weeks of culture the medium was exchanged and 2 weeks later 11 of the nutrient was added to the medium.

\section{Measurement of root growth}

The growth of transgenic roots was assessed as fresh and dry weight and by correlating the biomass growth with conductivity and sucrose uptake. For the fresh weight determination, the roots were gently pressed on filter paper to remove excess water, and weighed. The growth rate $(G R)$ was calculated using the formula [56]: $G R=$ final weight (g) - initial weight $(\mathrm{g}) /$ initial weight $(\mathrm{g}) \times 100 \%$.

The dry weight was determined after lyophilization. The conductivity (expressed in miliSiemens, $\mathrm{mS}$ ) was determined using a conductivity meter (model CC-317, Elmetron, Poland; sensitivitity $0.5 \%$ ). The sucrose concentration (expressed as percentage) was measured using a saccharimetr (model RR 10, PZO, Poland; sensitivity $0.1 \%$ ). The $\mathrm{pH}$ was determined using a pH-meter (model N5170, ELWRO, Poland; sensitivity 0.01).

The contents of three flasks of the transgenic hairy root line Pl 17 were harvested and analyzed for biomass, conductivity and sucrose concentration at 7 days intervals during the 8 -week experiment. Samples of the medium from bioreactor obtained with a sampler were tested for conductivity and sucrose uptake from the beginning of week 8 .

The convenient formula to describe the inverse relationship between biomass and conductivity during the shake flask culture was $\Delta m=a \Delta k+b$ where $\Delta m$ (g) was the increase of dry biomass of hairy roots and $\Delta k(\mathrm{mS} / \mathrm{cm})$ was the decrease in conductivity. The $a$ and $b$ values were found to be $0.20(0.03)$ and $-0.08(0.07)$ respectively. The correlation coefficient was $0.95(P=0.0001)$.

The relationship between biomass and sucrose level was described by the formula $\Delta m=a \Delta s+b$ where $\Delta m$ (g) was the increase of dry biomass of hairy roots and $\Delta s(\%)$ was the decrease of sucrose level. The $a$ and $b$ values were found to be $0.30(0.03)$ and $-0.23(0.06)$, respectively. The correlation coefficient was $0.98(P=0.0001)$.

\section{Determination of saponins accumulation}

The saponin content was determined in the hairy roots lines Pl 17 and Pl 6 cultivated in flasks and in the line Pl 17 cultured in the bioreactor and compared with the accumulation of saponins in 6-year-old roots from the field cultivation. Mother plant used as a control was derived from in vitro culture. Plantlets before transfer to the soil were micropropagated as mentioned above [34]. The 6-year-old roots were chosen for the experiment because the saponin content increases with the age of the plant.

Dried, pulverized roots ( $2 \mathrm{~g})$ were put in a Soxhlet apparatus, soaked in methanol $(150 \mathrm{ml})$, allowed to macerate for 17 hours and next refluxed for 6 hours, left overnight, and finally filtered. The filtrate was evaporated in vacuum to afford a dark brown residue, which was dissolved in methanol $(50 \mathrm{ml})$. The methanol solution was poured into water $(1 / 1, v / v)$ and then methanol was removed in vacuum. The aqueous residue was successively extracted 10 times with diethyl ether $(4 / 1, \mathrm{v} / \mathrm{v})$ and subsequently 5 times with butanol saturated with water $(4 / 1, \mathrm{v} / \mathrm{v})$. The butanol layers were combined and evaporated in vacuum. The residue was dissolved in methanol $(10 \mathrm{ml})$. The methanol solution was poured into diethyl ether $(35 \mathrm{ml})$. The resulting precipitates of the crude saponins were collected by filtration and dried at $105^{\circ} \mathrm{C}$ to constant weight.

The mean value and standard deviation represent the replicate of six determinations. Normal distribution and homogeneity of variances of the data were checked with the Shapiro-Wilk test and the Leaven's test respectively. Since in any of the analyzed groups there was not enough evidence to reject null hypothesis $(P>0.05)$, subsequent statistical evaluation of significance was performed by ANOVA test. Post-hoc Dunnett's test was used for individual comparison of groups with the control group. Otherwise LSD test (least significant differences) was used. Calculations were performed using the STATISTICA version 9.0 software.

\section{Results}

\section{Induction of hairy roots}

Infections of Platycodon grandiflorum leaf explants with Agrobacterium rhizogenes ATCC 15834 resulted in formation of hairy roots (Fig. 1). An analysis of amplification products obtained in PCR confirmed the presence of the rolA, rolB and rolC genes in genomic DNA of hairy roots. PCR analysis result for the P. grandiflorum are shown in Fig. 2.

\section{Studies in shake flask cultures}

Platycodon grandiflorum hairy roots grew in liquid WPM medium without growth regulators and demonstrated a typical transformed phenotype. Hairy roots tended to proliferate root hairs, which appeared to be white and healthy (Fig. 3). During the culture of the transgenic line Pl 17 the phases of growth typical of hairy roots were observed: lag phase, exponential phase and stationary phase. The exponential phase started from week 2 of growth and lasted until week 7 . The growth rate after this phase was $3770 \%$.

During this phase the considerable biomass increase was correlated with a marked decrease in the sucrose level in the 


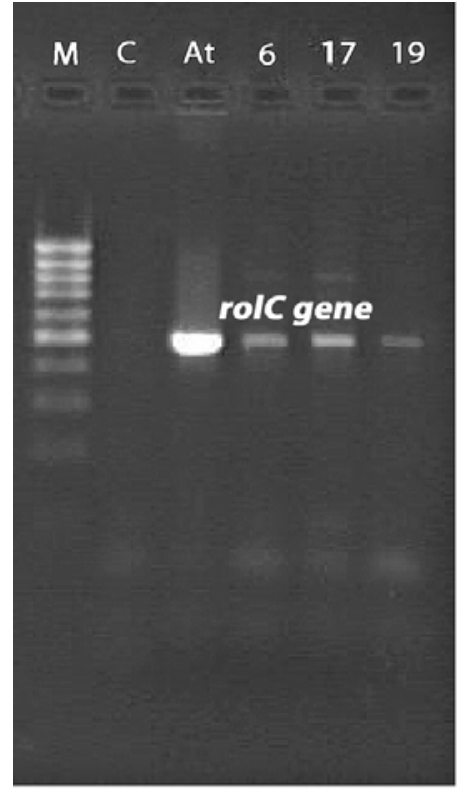

rolC

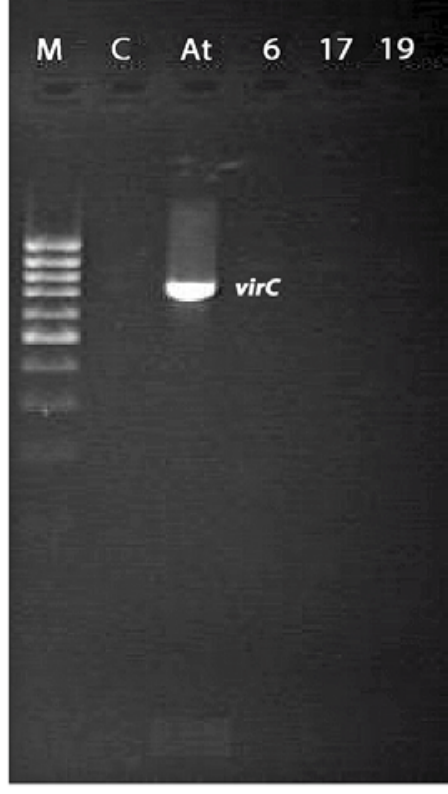

virC

Fig. 2 Confirmation of transformation in hairy root lines by PCR reaction. The pictures shows agarose gel electrophoresis of PCRamplified products performed with rolC primers and $v i r C$ primers. Non transformed roots of Platycodon grandiflorum, clone No. 26 were used as negative control (C), while template for the positive (At) control was Agrobacterium rhizogenes, strain 15834.100 bp DNA ladder was used for the estimation of DNA fragment size. No. 6,17 and 19 corresponds to the transformed roots of P. grandiflorum.

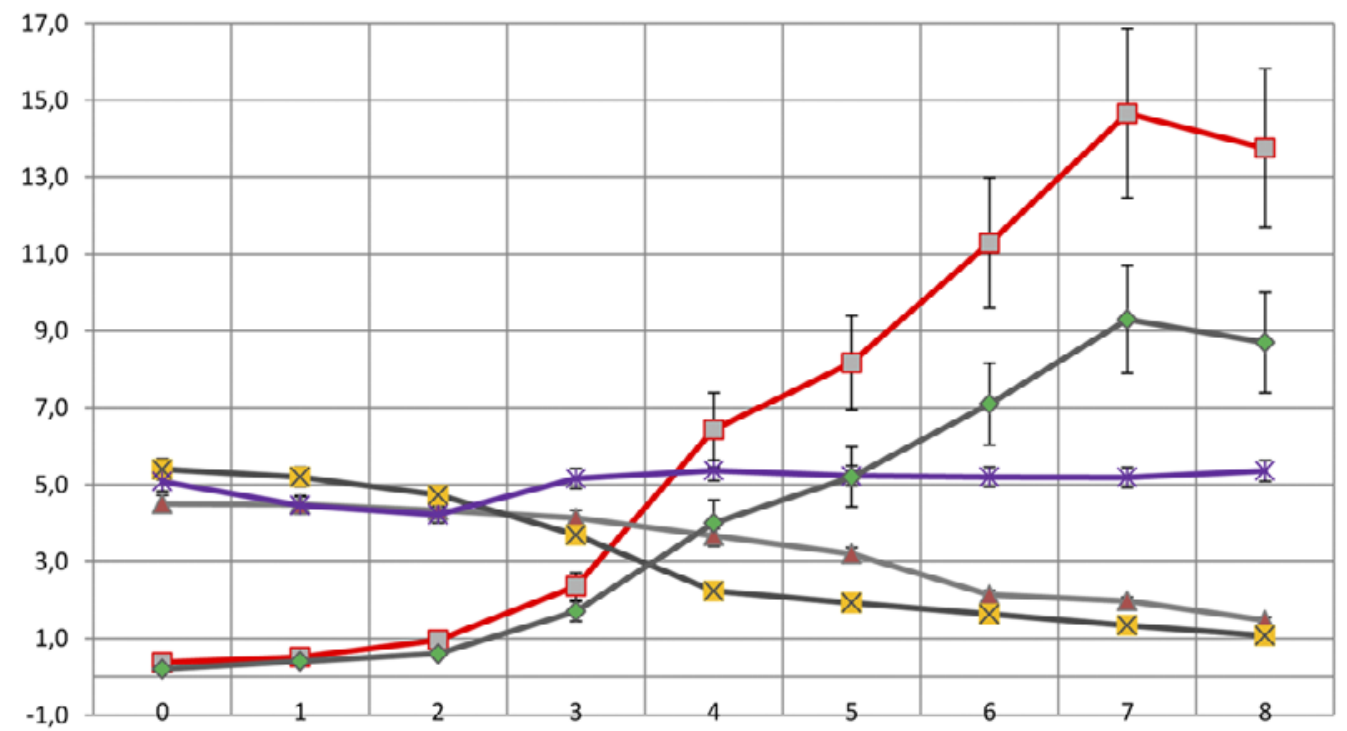

time (week)

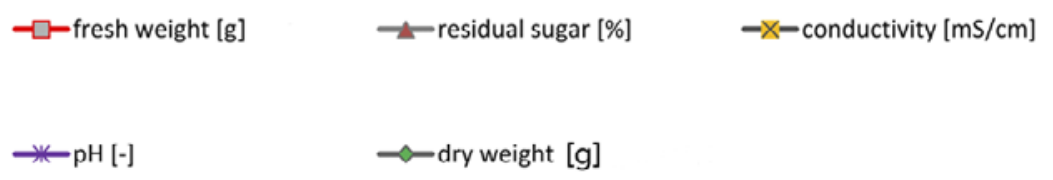

Fig. 3 Changes in medium conductivity and sucrose concentration in the medium and the biomass decrease during the culture of Platycodon grandiflorum hairy root line Pl 17 in shake flasks. Each point is the mean value of three estimates (three Erlenmeyer flasks from one passage). 
medium (from 4.0 to $1.7 \%$ ) and conductivity (from 5.30 to $1.24 \mathrm{mS} / \mathrm{cm}$ ). The changes of hairy root biomass, conductivity, $\mathrm{pH}$ and sucrose level is shown in Fig. 3.

Post-hoc Dunett's test revealed that saponin concentration was significantly higher in both hairy roots lines $(P<<$ 0.0001 for line $\mathrm{Pl} 6, P=0.0005$ for line $\mathrm{Pl} 17)$ compared to normal roots derived from the field cultivation. The highest concentration was described for line Pl $6(0.0264<<P<<$ $0.0001)$. The mean values $[\mathrm{g} / 100 \mathrm{~g}$ d.w. $(\mathrm{g} \%)]$ of saponins concentrations for line $\mathrm{Pl} 6$, line $\mathrm{Pl} 17$ and field roots were 6.92 (0.88), $5.82(0.84)$ and $4.02(0.51)$ respectively.

\section{Bioreactor studies}

In our study, $P$. grandiflorum hairy roots grew well in a mist bioreactor. The roots were supported on a steel nest and sprinkled with nutrient WPM supplemented with $40 \mathrm{~g} / \mathrm{l}$ sucrose. The roots occupied the whole space available and their growth was demonstrated by enhanced root length and lateral root induction (Fig. 4). After 8 weeks of culture the medium was replaced. The kinetic parameters from the medium poured out from the bioreactor provided evidence for considerable consumption of the mineral components and sucrose. The conductivity was decreased from 5.25 to $2.11 \mathrm{mS} \mathrm{cm}^{-1}$ and sucrose concentration decreased from 4.8 to $2.5 \%$. In week 8 of culture a very rapid growth of

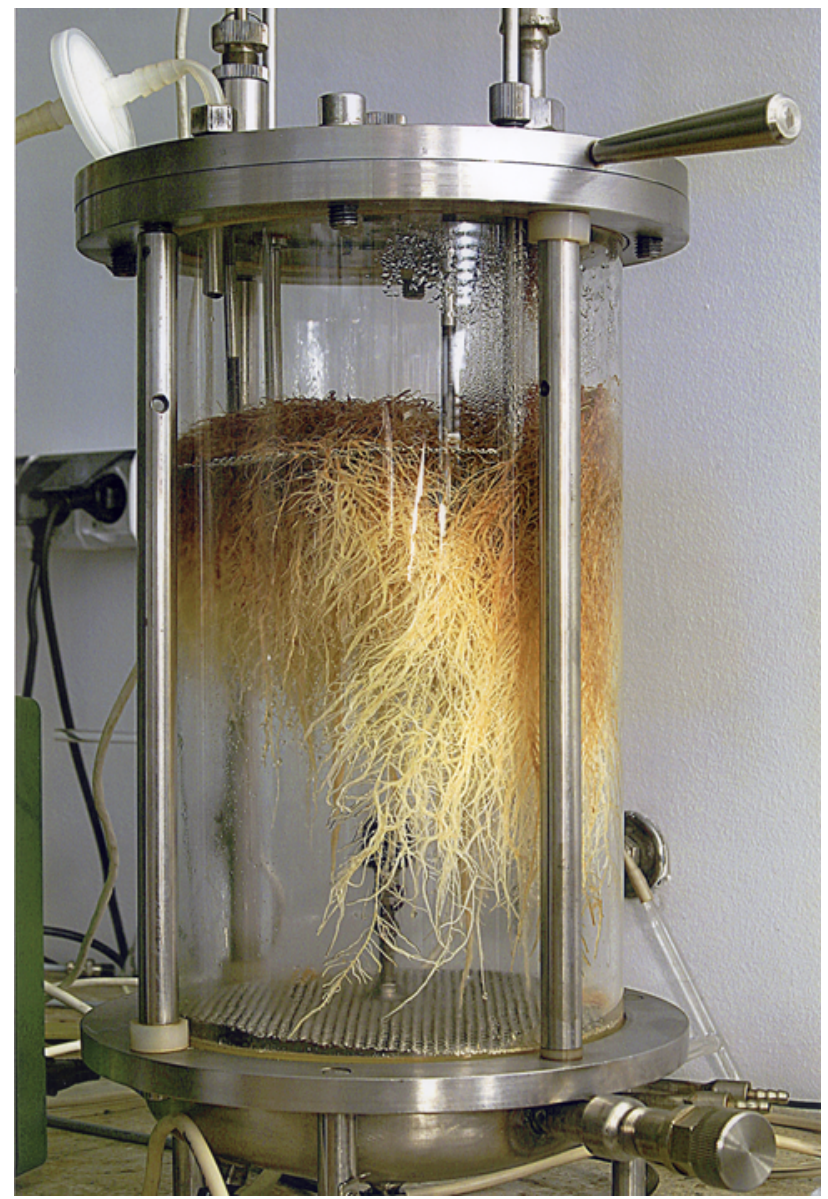

Fig. 4 Platycodon grandiflorum hairy root culture of Pl 17 line in 5-1 mist bioreactor with liquid WPM medium supplemented with $40 \mathrm{~g} / \mathrm{l}$ sucrose, cultivated for 12 weeks. After 8 weeks of culture medium was exchanged and 2 weeks later medium was refilled by 11 of nutrient.
P. grandiflorum hairy roots was observed which was correlated with fast exhaustion of the medium components. The conductivity decreased from 5.25 to $1.74 \mathrm{mS} / \mathrm{cm}$ and the sucrose concentration fell from 4.4 to $3.4 \%$. The differences in conductivity and sucrose concentrations in the medium observed over the entire period of $P$. grandiflorum hairy root line Pl 17 culture in the bioreactor are shown in Fig. 5.

After culture day 71, when 11 of medium was added, the conductivity and sucrose concentration did not change as much as described above. It was due to the necrosis of the hairy roots occupying the top of the mesh, which were not sufficiently sprinkled with the medium. The hairy roots from the bottom of the mesh continued to demonstrate enhanced length and lateral roots were induced.

After the culture of $P$. grandiflorum hairy roots in the bioreactor $591 \mathrm{~g}$ of fresh biomass was obtained, which corresponded to $36.6 \mathrm{~g}$ of dry weight (Fig. 6). The growth rate of the hairy roots was $3180 \%$, comparable to the growth rate of hairy roots of the same line, when the exponential phase of growth in the shake flasks was completed. Moreover, comparable saponin contents were observed during both cultures of the hairy roots line $17(P=0.80)$. The mean saponin content of the hairy roots grown in the bioreactor was $5.93 \mathrm{~g} \%(0.48)$.

\section{Discussion}

For the experiment WPM medium with increased up to $40 \mathrm{~g} / \mathrm{l}$ amount of saccharose was chosen. Our previous study [34] showed that plantlets growing on MS medium with saccharose at a dose $40 \mathrm{~g} / \mathrm{l}$ developed thicker roots compared to those cultivated on the MS medium with saccharose at a dose $30 \mathrm{~g} / \mathrm{l}$.

Hairy root growth can be easily monitored by measurement of the conductivity. An inverse relationship between biomass and conductivity was observed not only by our research team, but by Suresh et al. [57,58] as well. Authors [57] described this relationship occurred in hairy root culture of Tagetes patula by the same formula as used in P. grandiflorum hairy root shake flask cultures. The decrease in conductivity can be attributed to the intake of nutrients by growing hairy roots leading to a decrease in the number of ions.

Besides our experiment, an inverse relationship between biomass and sucrose level was observed by SykłowskaBaranek et al. [59]. However, our results indicate that this correlation is weaker than that between biomass increase and conductivity decrease.

A nutrient mist bioreactor, used in this study, offers some advantages for growing hairy roots. It provides an environment with a low shear stress, where hairy roots receive rapid replenishment of nutrients and removal of toxic metabolites [60]. What is more, the dispersal of liquid medium in the gas phase could also facilitate better oxygen transfer due to its higher solubility in air than in aqueous medium [61,62]. A very similar type of bioreactor was used by Kuźma et al. [63]. In their study, Salvia sclarea hairy roots elicited by methyl jasmonate in bioreactor produced 9 and 3.8 times as much aethiopinone and salvipisone respectively, as elicited roots cultured in shake flasks. The nutrient sprinkle bioreactor 


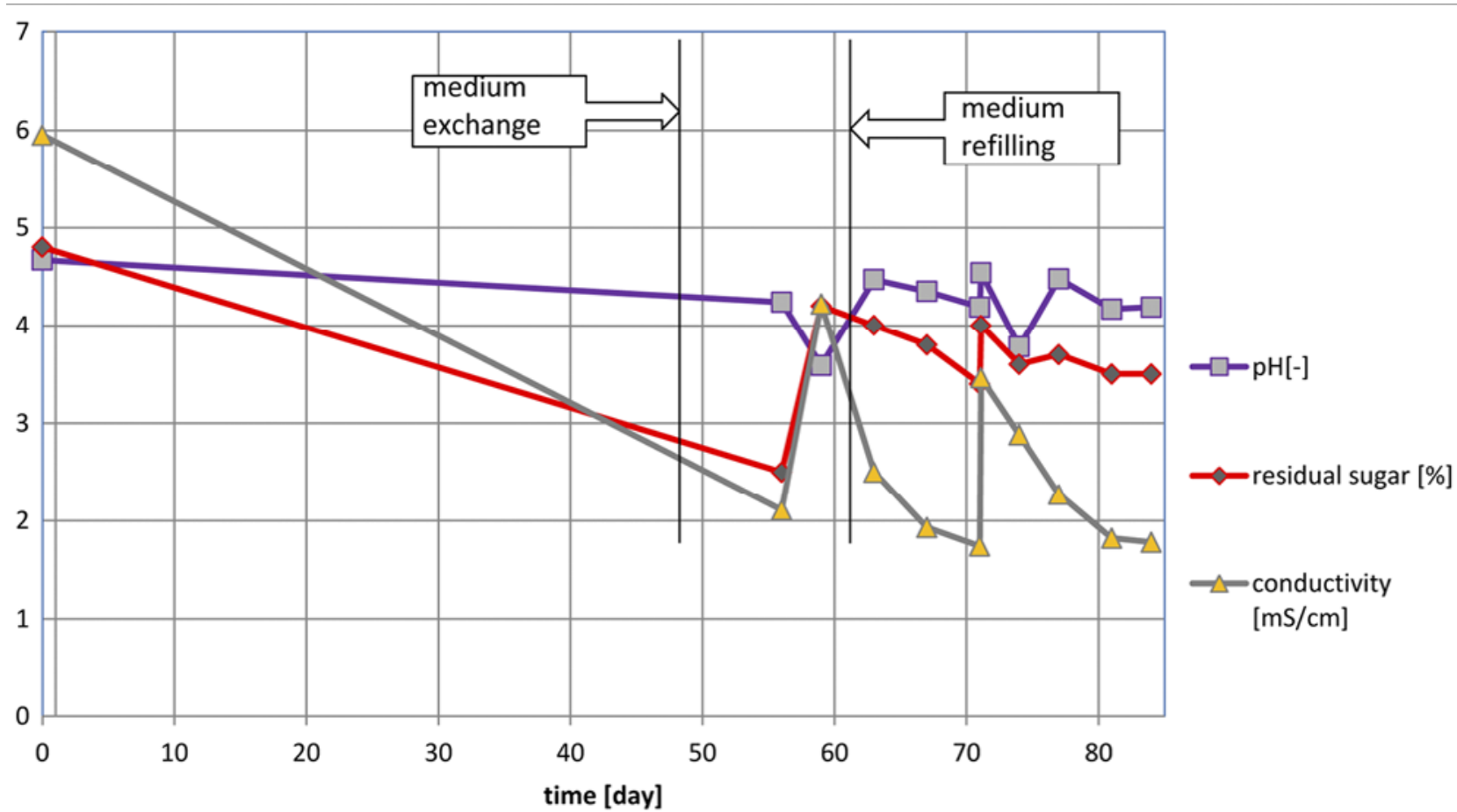

Fig. 5 Changes in medium conductivity and sucrose concentration in the medium during the culture of Platycodon grandiflorum hairy root line Pl 17 in bioreactor.

was used as well by Kochan et al. [64] to provide the culture of Panax quinquefolium hairy roots. The contents of six examined ginsenoside showed twofold higher level in hairy roots cultivated in bioreactor than in roots growing in the shaken flasks.

The medium exchange during Platycodon grandiflorum hairy root culture in the bioreactor considerably accelerated sucrose and nutrient consumption. These results were consistent with the experiment by Pawłowska and Chmiel [65]. They cultured Paulownia tomentosa hairy roots in a similar bioreactor using the same medium. After the entire medium exchange they observed a greater biomass increase and culture productivity than with the medium refilled with phosphate or ammonium nitrate only. The similar observations were done as well by Palazon et al. [66]. The medium exchange in the bioreactor was the requirement of the increased productivity of ginsenosides.

In the latter part of the P. grandiflorum hairy root culture in the bioreactor cell lysis in a population of roots put on the top of the mesh occurred, possibly because the culture medium did not remain in suitable contact with the cultured roots. Thus a modification of this bioreactor construction is required. Liu et al. [60] fitted a concentric draught tube with holes into their mist bioreactor which ensured better mist distribution compared to a standard mist bioreactor. The alternative can be the Wave bioreactor employment [66], in which the medium reach to any cell. The satisfactory results were received by Jeong and Park as well [67]. The most effective mass production of Panax ginseng hairy roots was achieved in several differently sized air bubble bioreactors compared to all other bioreactor types.

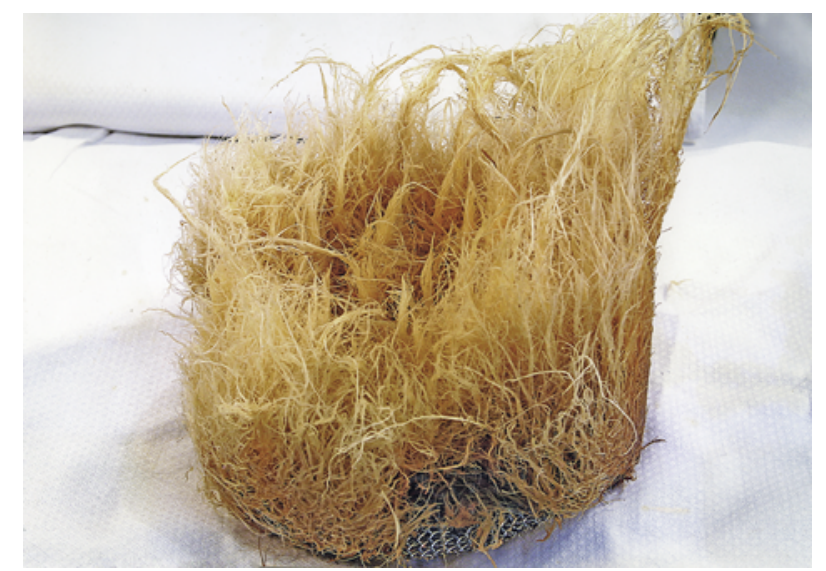

Fig. 6 Platycodon grandiflorum hairy root biomass of transgenic line Pl 17 after the culture period of 12 weeks in 5-1 bioreactor with liquid WPM medium supplemented with $40 \mathrm{~g} / \mathrm{l}$ sucrose.

\section{Conclusions}

Saponins obtained from the roots of Platycodon grandiflorum are valuable compounds showing a broad spectrum of pharmacological activities. It is noteworthy that the hairy root culture of $P$. grandiflorum presents weak haemolytic activity what makes this plant material safe in use [17]. Our results suggest that the hairy root culture is a good alternative to the field cultivation of the plant. 


\section{Acknowledgments}

This study was supported by the Polish Ministry of Science and Higher Education, grant No. NN 405219539.

We thank Dr. D. Ruszkowski from Laboratory Of Environmental Contamination Analysis, University of Warsaw, for his help during chemical analysis of saponin.

\section{Authors' contributions}

The following declarations about authors' contributions to the research have been made: concept of the study: NU, WJS; laboratory research and data analyses: NU, JG, WJS; writing of the manuscript: NU, JG, OO, WJS.

\section{References}

1. Kim Y, Wyslouzil BE, Weathers PJ. Secondary metabolism of hairy root cultures in bioreactors. In Vitro Cell Dev Biol Plant. 2002;38(1):1-10. http://dx.doi.org/10.1079/IVP2001243

2. Guillon S, Trémouillaux-Guiller J, Pati PK, Rideau M, Gantet P. Hairy root research: recent scenario and exciting prospects. Curr Opin Plant Biol. 2006;9(3):341-346. http://dx.doi.org/10.1016/j.pbi.2006.03.008

3. Liu C. Bioreactor: a power tool for pharmaceutical production from plant hairy root cultures. J Biotech. 2008;136:S496. http://dx.doi. org/10.1016/j.jbiotec.2008.07.1162

4. Ahn KS, Hahn BS, Kwack KB, Lee EB, Kim YS. Platycodin D-induced apoptosis through nuclear factor- $\kappa \mathrm{B}$ activation in immortalized keratinocytes. Eur J Pharmacol. 2006;537(1-3):1-11. http://dx.doi. org/10.1016/j.ejphar.2006.03.012

5. Zhang L, Liu ZH, Tian JK. Cytotoxic triterpenoid saponins from the roots of Platycodon grandiflorum. Molecules. 2007;12(4):832-841. http://dx.doi.org/10.3390/12040832

6. Kim J Y, Park KW, Moon KD, Lee MK, Choi J, Yee ST, et al. Induction of apoptosis in HT-29 colon cancer cells by crude saponin from Platycodi radix. Food Chem Toxic. 2008;46(12):3753-3758. http:// dx.doi.org/http://dx.doi.org/10.1016/j.fct.2008.09.067

7. Lee KJ, Hwang SJ, Choi JH, Jeong HG. Saponins derived from the roots of Platycodon grandiflorum inhibit HT-1080 cell invasion and MMPs activities: Regulation of NF- $\mathrm{BB}$ activation via ROS signal pathway. Cancer Lett. 2008;268(2):233-243. http://dx.doi.org/10.1016/j. canlet.2008.03.058

8. Kim YP, Lee EB, Kim SY, Li D, Ban HS, Lim SS, et al. Inhibition of prostaglandin $\mathrm{E} 2$ production by platycodin $\mathrm{D}$ isolated from the root of Platycodon grandiflorum. Planta Med. 2001;67(4):362-364. http:// dx.doi.org/10.1055/s-2001-14317

9. Kim JY, Hwang YP, Kim DH, Han EH, Chung YC, Roh SH, et al. Inhibitory effect of the saponins derived from roots of Platycodon grandiflorum on carrageenan-induced inflammation. Biosci Biotechnol Biochem. 2006;70(4):858-864. http://dx.doi.org/10.1271/bbb.70.858

10. Lee K. Protective effect of saponins derived from roots of Platycodon grandiflorum on tert-butyl hydroperoxide-induced oxidative hepatotoxicity. Toxicol Lett. 2004;147(3):271-282. http://dx.doi.org/10.1016/j. toxlet.2003.12.002

11. Zhao HL, Cho KH, Ha YW, Jeong TS, Lee WS, Kim YS. Cholesterollowering effect of platycodin D in hypercholesterolemic ICR mice. Eur J Pharmacol. 2006;537(1-3):166-173. http://dx.doi.org/10.1016/j. ejphar.2006.03.032

12. Choi SS, Han EJ, Lee TH, Han KJ, Lee HK, Suh HW. Antinociceptive profiles of platycodin D in the mouse. Am J Chin Med. 2004;32(02):257-268. http://dx.doi.org/10.1142/S0192415X04001916

13. Xie Y, Pan H, Sun H, Li D. A promising balanced Th1 and Th2 directing immunological adjuvant, saponins from the root of Platycodon grandiflorum. Vaccine. 2008;26(31):3937-3945. http://dx.doi. org/10.1016/j.vaccine.2008.01.061

14. Xie Y, Sun HX, Li D. Platycodin D is a potent adjuvant of specific cellular and humoral immune responses against recombinant hepatitis B antigen. Vaccine. 2009;27(5):757-764. http://dx.doi.org/10.1016/j. vaccine.2008.11.029

15. Xie Y, Ye YP, Sun HX, Li D. Contribution of the glycidic moieties to the haemolytic and adjuvant activity of platycodigenin-type saponins from the root of Platycodon grandiflorum. Vaccine. 2008;26(27-28):34523460. http://dx.doi.org/10.1016/j.vaccine.2008.04.023
16. Jeong HM, Han EH, Jin YH, Hwang YP, Kim HG, Park BH, et al. Saponins from the roots of Platycodon grandiflorum stimulate osteoblast differentiation via p38 MAPK- and ERK-dependent RUNX2 activation. Food Chem Toxic. 2010;48(12):3362-3368. http://dx.doi. org/10.1016/j.fct.2010.09.005

17. Urbańska N, Nartowska J, Skorupska A, Ruszkowski D, Giebułtowicz J, Olszowska O. Determination and haemolytic activity of saponins in hairy root culture of Platycodon grandiforum A. DC. Herba Pol. 2009;55(3):103-108.

18. Pharmacopoeia Commission of PRC. Pharmacopoeia of the People's Republic of China (1988 English edition). Beijing: People's Medical Publishing House; 1988.

19. Ha IJ, Kang M, Na YC, Park Y, Kim YS. Preparative separation of minor saponins from Platycodi radix by high-speed counter-current chromatography. J Sep Sci. 2011;34(19):2559-2565. http://dx.doi. org/10.1002/jssc.201100326

20. Zhan Q, Zhang F, Sun L, Wu Z, Chen W. Two new oleanane-type triterpenoids from Platycodi radix and anti-proliferative activity in HSC-T6 cells. Molecules. 2012;17(12):14899-14907. http://dx.doi. org/10.3390/molecules 171214899

21. WHO. WHO monographs on selected medicinal plants. Geneva: WHO; 1999. (vol 1).

22. Yoo DS, Choi YH, Cha MR, Lee BH, Kim SJ, Yon GH, et al. HPLCELSD analysis of 18 platycosides from balloon flower roots (Platycodi radix) sourced from various regions in Korea and geographical clustering of the cultivation areas. Food Chem. 2011;129(2):645-651. http://dx.doi.org/10.1016/j.foodchem.2011.04.106

23. Kim YK, Kim JK, Kim YB, Lee S, Kim SU, Park SU. Enhanced accumulation of phytosterol and triterpene in hairy root cultures of Platycodon grandiflorum by overexpression of Panax ginseng 3-hydroxy-3-methylglutaryl-coenzyme A reductase. J Agric Food Chem. 2013;61(8):1928-1934. http://dx.doi.org/10.1021/jf304911t

24. Tada H, Shimomura K, Ishimaru K. Polyacetylenes in Platycodon grandiflorum hairy root and Campanulaceous plants. J Plant Physiol. 1995;145(1-2):7-10. http://dx.doi.org/10.1016/S0176-1617(11)81838-9

25. Lee JY, Yoon JW, Kim CT, Lim ST. Antioxidant activity of phenylpropanoid esters isolated and identified from Platycodon grandiflorum A. DC. Phytochemistry. 2004;65(22):3033-3039. http://dx.doi. org/10.1016/j.phytochem.2004.08.030

26. Fu WW, Dou DQ, Shimizu N, Takeda T, Pei YH, Chen YJ. Studies on the chemical constituents from the roots of Platycodon grandiflorum. J Nat Med. 2006;60(1):68-72. http://dx.doi.org/10.1007/ s11418-005-0008-0

27. Liu W, Liu H, Han M. Polysaccharides from Platycodon grandiflorum. Chem Nat Compd. 2013;48(6):927-929. http://dx.doi.org/10.1007/ s10600-013-0430-6

28. Xu Y, Dong Q, Qiu H, Cong R, Ding K. Structural characterization of an arabinogalactan from Platycodon grandiflorum roots and antiangiogenic activity of its sulfated derivative. Biomacromolecules. 2010;11(10):2558-2566. http://dx.doi.org/10.1021/bm100402n

29. Xu Y, Dong Q, Qiu H, Ma CW, Ding K. A homogalacturonan from the radix of Platycodon grandiflorum and the anti-angiogenesis activity of poly-/oligogalacturonic acids derived therefrom. Carbohydr Res. 2011;346(13):1930-1936. http://dx.doi.org/10.1016/j. carres.2011.05.011

30. Reininger EA, Bauer R. Prostaglandin-H-synthase (PGHS)-1 and -2 microtiter assays for the testing of herbal drugs and in vitro inhibition of PGHS-isoenzyms by polyunsaturated fatty acids from Platycodi radix. Phytomedicine. 2006;13(3):164-169. http://dx.doi.org/10.1016/j. phymed.2005.03.006

31. Jeong CH, Choi GN, Kim JH, Kwak JH, Kim DO, Kim YJ, et al. Antioxidant activities from the aerial parts of Platycodon grandiflorum. Food Chem. 2010;118(2):278-282. http://dx.doi.org/10.1016/j. foodchem.2009.04.134

32. Inada A, Murata H, Somekawa M, Nakanishi T. Phytochemical studies of seeds of medicinal plants. II. A new dihydroflavonol glycoside and a new 3-methyl-1-butanol glycoside from seeds of Platycodon grandiflorum A. de Candolle. Chem Pharm Bull Tokyo. 1992;40(11):3081-3083.

33. Jang DS, Lee YM, Jeong IH, Kim JS. Constituents of the flowers of 
Platycodon grandiflorum with inhibitory activity on advanced glycation end products and rat lens aldose reductase in vitro. Arch Pharm Res. 2010;33(6):875-880. http://dx.doi.org/10.1007/s12272-010-0610-x

34. Micropropagation of Platycodon grandiflorum. In: Conference proceedings of the 53. conference of Polish Botanical Society: Polish nature in the natural heritage of Europe. 6-11 September 2004, Torun, Bydgoszcz, Poland. Toruń: Polish Botanical Society; 2004. p. 120.

35. Kim SW, Liu JR. Somatic embryogenesis and plant regeneration in zygotic embryo cultures of balloon flower. Plant Cell Tissue Organ Cult. 1999;58(3):227-230. http://dx.doi.org/10.1023/A:1006338024745

36. Hosoki T, Mochida M. Mass propagation of balloon flower (Platycodon grandiflorum A. DC.) by repeated shoot-sectioning and separation of axillary shoot. Seibutsu Kankyo Chosetsu. 1995;33(3):213-216. http:// dx.doi.org/10.2525/ecb1963.33.213

37. Iapichino G, Airò M. Micropropagation of Platycodon grandiflorus. Italus Hortus. 2009;16(2):128-131.

38. Murashige T, Skoog F. A revised medium for rapid growth and bio assays with tobacco tissue cultures. Physiol Plant. 1962;15(3):473-497. http://dx.doi.org/10.1111/j.1399-3054.1962.tb08052.x

39. Gamborg OL, Miller RA, Ojima K. Nutrient requirements of suspension cultures of soybean root cells. Exp Cell Res. 1968;50(1):151-158. http://dx.doi.org/10.1016/0014-4827(68)90403-5

40. Lloyd G, McCown B. Commercially-feasible micropropagation of mountain laurel, Kalmia latifolia, by use of shoot-tip culture. Comb Proc Int Plant Propagators Soc. 1980;30:421-427.

41. Bernard F, Moghbel N, Hassannejad S. Treatment of licorice seeds with colchicine: changes in seedling DNA levels and anthocyanin and glycyrrhizic acid contents of derived callus cultures. Nat Prod Commun. 2012;7(11):1457-1460.

42. Wongwicha W, Tanaka H, Shoyama Y, Putalun W. Methyl jasmonate elicitation enhances glycyrrhizin production in Glycyrrhiza inflata hairy roots cultures. Z Naturforsch C. 2011;66(7-8):423-428. http:// dx.doi.org/10.5560/ZNC.2011.66c0423

43. Yin S, Zhang Y, Gao W, Wang J, Man S, Liu H. Effects of nitrogen source and phosphate concentration on biomass and metabolites accumulation in adventitious root culture of Glycyrrhiza uralensis Fisch. Acta Physiol Plant. 2014;36(4):915-921. http://dx.doi.org/10.1007/ s11738-013-1470-Z

44. Shabani L, Ehsanpour AA, Asghari G, Emami J. Glycyrrhizin production by in vitro cultured Glycyrrhiza glabra elicited by methyl Jasmonate and salicylic acid. Russ J Plant Physiol. 2009;56(5):621-626. http://dx.doi.org/10.1134/S1021443709050069

45. Lu HY, Liu JM, Zhang HC, Yin T, Gao SL. Ri-mediated transformation of Glycyrrhiza uralensis with a squalene synthase gene (GuSQS1) for production of glycyrrhizin. Plant Mol Biol Rep. 2008;26(1):1-11. http://dx.doi.org/10.1007/s11105-008-0018-7

46. Li YL, Yang Y, Fu CH, Yu LJ. Production of glycyrrhizin in cell suspension of Glycyrrhiza inflata Batalin cultured in bioreactor. Biotechnol Biotechnol Equip. 2012;26(5):3231-3235. http://dx.doi.org/10.5504/ BBEQ.2012.0083

47. Wang J, Zhang J, Gao W, Wang Q, Yin S, Liu H, et al. Identification of triterpenoids and flavonoids, step-wise aeration treatment as well as antioxidant capacity of Glycyrrhiza uralensis Fisch. cell. Ind Crops Prod. 2013;49:675-681. http://dx.doi.org/10.1016/j.indcrop.2013.05.021

48. Yu KW, Gao WY, Son SH, Paek KY. Improvement of ginsenoside production by jasmonic acid and some other elicitors in hairy root culture of ginseng (Panax ginseng C.A. Meyer). In Vitro Cell Dev Biol Plant. 2000;36(5):424-428. http://dx.doi.org/10.1007/s11627-000-0077-4

49. Yu KW, Gao W, Hahn EJ, Paek KY. Jasmonic acid improves ginsenoside accumulation in adventitious root culture of Panax ginseng C.A. Meyer. Biochem Eng J. 2002;11(2-3):211-215. http://dx.doi.org/10.1016/ S1369-703X(02)00029-3

50. Huang C, Zhong JJ. Elicitation of ginsenoside biosynthesis in cell cultures of Panax ginseng by vanadate. Process Biochem. 2013;48(8):12271234. http://dx.doi.org/10.1016/j.procbio.2013.05.019

51. Akalezi CO, Liu S, Li QS, Yu JT, Zhong JJ. Combined effects of initial sucrose concentration and inoculum size on cell growth and ginseng saponin production by suspension cultures of Panax ginseng. Process Biochem. 1999;34(6-7):639-642. http://dx.doi.org/10.1016/ S0032-9592(98)00132-0

52. Yu KW, Murthy HN, Hahn EJ, Paek KY. Ginsenoside production by hairy root cultures of Panax ginseng: influence of temperature and light quality. Biochem Eng J. 2005;23(1):53-56. http://dx.doi. org/10.1016/j.bej.2004.07.001

53. Wu J, Zhong J. Production of ginseng and its bioactive components in plant cell culture: current technological and applied aspects. J Biotech. 1999;68(2-3):89-99. http://dx.doi.org/10.1016/S0168-1656(98)00195-3

54. Hooykaas PJJ, Klapwijk PM, Nuti MP, Schilperoort RA, Rorsch A. Transfer of the Agrobacterium tumefaciens TI plasmid to avirulent Agrobacteria and to Rhizobium ex planta. J Gen Microbiol. 1977;98(2):477-484. http://dx.doi.org/10.1099/00221287-98-2-477

55. Vervliet G, Holsters M, Teuchy H, van Montagu M, Schell J. Characterization of different plaque-forming and defective temperate phages in Agrobacterium strains. J Gen Virol. 1975;26(1):33-48. http://dx.doi. org/10.1099/0022-1317-26-1-33

56. Street HE, Henshaw GG. Introduction and employed in plant tissue culture. In: Willmer EN, editor. Cells and tissue culture. London: Academic Press; 1966. p. 459-532. (vol 3).

57. Suresh B, Rajasekaran T, Rao SR, Raghavarao KSMS, Ravishankar GA. Studies on osmolarity, conductivity and mass transfer for selection of a bioreactor for Tagetes patula L. hairy roots. Process Biochem. 2001;36(10):987-993. http://dx.doi.org/10.1016/ S0032-9592(01)00132-7

58. Suresh B, Bais HP, Raghavarao KSMS, Ravishankar GA, Ghildyal NP. Comparative evaluation of bioreactor design using Tagetes patula $\mathrm{L}$. hairy roots as a model system. Process Biochem. 2005;40(5):15091515. http://dx.doi.org/10.1016/j.procbio.2003.10.017

59. Sykłowska-Baranek K, Pietrosiuk A, Gawron A, Kawiak A, Łojkowska E, Jeziorek M, et al. Enhanced production of antitumour naphthoquinones in transgenic hairy root lines of Lithospermum canescens. Plant Cell Tissue Organ Cult. 2012;108(2):213-219. http://dx.doi. org/10.1007/s11240-011-0032-6

60. Liu CZ, Wang YC, Zhao B, Guo C, Ouyang F, Ye HC, et al. Development of a nutrient mist bioreactor for growth of hairy roots. In Vitro Cell Dev Biol Plant. 1999;35(3):271-274. http://dx.doi.org/10.1007/ s11627-999-0091-0

61. Srivastava $S$, Srivastava AK. In vitro azadirachtin production by hairy root cultivation of Azadirachta indica in nutrient mist bioreactor. Appl Biochem Biotechnol. 2012;166(2):365-378. http://dx.doi.org/10.1007/ s12010-011-9430-9

62. Weathers PJ, Wyslouzil BE, Wobbe KK, Kim YJ, Yigit E. The biological response of hairy roots to $\mathrm{O}_{2}$ levels in bioreactors. In Vitro Cell Dev Biol Plant. 1999;35(4):286-289. http://dx.doi.org/10.1007/ s11627-999-0035-8

63. Kuźma Ł, Bruchajzer E, Wysokińska H. Methyl jasmonate effect on diterpenoid accumulation in Salvia sclarea hairy root culture in shake flasks and sprinkle bioreactor. Enzyme Microb Technol. 2009;44(67):406-410. http://dx.doi.org/10.1016/j.enzmictec.2009.01.005

64. Kochan E, Królicka A, Chmiel A. Growth and ginsenoside production in Panax quinquefolium hairy roots cultivated in flasks and nutrient sprinkle bioreactor. Acta Physiol Plant. 2012;34(4):1513-1518. http:// dx.doi.org/10.1007/s11738-012-0949-3

65. Pawłowska B, Chmiel A. Scaling up the Paulownia tomentosa hairy roots culture. BioTechnologia. 2003;4(63):142-153.

66. Palazón J, Mallol A, Eibl R, Lettenbauer C, Cusidó RM, Piñol MT. Growth and ginsenoside production in hairy root cultures of Panax ginseng using a novel bioreactor. Planta Med. 2003;69(4):344-349. http://dx.doi.org/10.1055/s-2003-38873

67. Jeong GT, Park DH. Comparative evaluation of modified bioreactors for enhancement of growth and secondary metabolite biosynthesis using Panax ginseng hairy roots. Biotechnol Bioprocess Eng. 2005;10(6):528-534. http://dx.doi.org/10.1007/BF02932289 